Behavior and Social Issues, 17, 1-5 (2008). (C) Sandy Hobbs. Readers of this article may copy it without the copyright owner's permission, if the author and publisher are acknowledged in the copy and the copy is used for educational, not-for-profit purposes.

\title{
GUEST EDITORIAL: BEHAVIOR ANALYSIS IN ITS Historical and Cultural Context
}

\section{Sandy Hobbs \\ University of the West of Scotland}

These reflections arise from recent discussion on the BFSR listserv regarding the prioritization of social problems. I have not participated actively in the discussion, although I have followed it closely. The "blogging" type of communication which the technology appears to encourage does not seem to me to be a fruitful way of developing arguments. The points which follow, although presented in rather schematic terms, would not have fitted easily into the electronic debate as it was conducted.

Since most people who read these notes do not know me, it may be helpful to introduce myself by making three points. First, I have been intellectually committed to radical behaviorism since my student days, but have generally worked in circumstances which made explicit advocacy of such a position difficult. Second, since the 1970s I have from time to time published papers on what might be termed the "social psychology of knowledge," ranging from urban myths (e.g., Hobbs \& Cornwell, 1991) to scholarly misinterpretations of Skinner (e.g., Hobbs, 2005). Third, for about twenty years, I have been researching child labor. This is a social issue which was not explicitly mentioned in the lists of problems which emerged in the listserv discussions, but which is obviously related to at least two topics which were, namely poverty and education. (This and other aspects of worldwide child labor discussed below are dealt with by Hobbs, McKechnie \& Lavalette, 1999; McKechnie \& Hobbs, 1998; and McKechnie \& Hobbs, 2002).

I hope I shall not be regarded as unnecessarily pessimistic, if I start by referring to some of the failures of behavior analysis. In the 1960s, Skinner and others attempted to revolutionize education by what were termed at the time "teaching machines." Skinner himself saw the outcome of their efforts as essentially a failure (Skinner, 1984). Although it might be possible to argue that there were some long term benefits to education which emerged from the work on programmed learning, it is clear that behaviorist concepts did not take hold in education in anything like the way that Skinner seems to have hoped.

More recently, we have a situation in which the methods of behavior analysis have achieved remarkable success in dealing with some of the apparently intractable problems associated with autism. Yet despite these successes, hostility to the behavior analytic approach has been extreme and resistance to the use of such methods has been very strong. (See Keenan, 2004.)

Both of these examples may be regarded as referring to the application of behavior analysis. However, there is another sort of historical failure which I believe needs to be acknowledged, namely the failure of behaviorism to become the central force in scientific psychology. In my view, behaviorism in essence is the rigorous application to human 
HOBBS

behavior of the methods and assumptions which have been successfully applied to physical and biological phenomena. Many psychologists probably aim to be "scientific" but have at the same time rejected behaviorism. This rejection is quite deep-seated. A look at a few elementary textbooks will show that students are told that for a time behaviorism dominated psychology but was overthrown by a "Cognitive Revolution" in the mid-twentieth century. (See, for example, Hackenbury \& Hackenbury, 1997, p. 10.) This account conveniently overlooks the fact that the mid-twentieth century was the time when radical behaviorism began to grow and flourish. However, although the factual inaccuracies of such a version of history are significant, more important is to ask why this false version of history is allowed to thrive. We may also ask what can be done to make behaviorism more widely understood and accepted in the community of psychologists.

Behaviorism's problems in achieving acceptance are not unique. Darwin and Wallace's theory of evolution by natural selection is accepted as correct and productive by the overwhelming majority of scientists in the field. Yet, a century and a half after it was first published it is still the subject to strong opposition, largely from people outside the scientific community. That opposition is often characterised as religious in nature. However, I suggest that it is more fruitful to see such "religious" behaviour as an aspect of a wider form, namely cultural behavior. The behavior we are dealing with here is verbal, and verbal behavior is sustained in many ways. "Scientific" verbal behavior ideally involves testing concepts against evidence. However, reality does not always correspond to that ideal. Recently, Mecca Chiesa and I have published an account of the use of the term "Hawthorne Effect" in psychology and related disciplines. This phrase flourishes in the discussion of social behavior even although the original research which gave rise to it was deeply flawed. Even more significant is the fact that the term is used in varied, often contradictory, ways (Chiesa \& Hobbs, 2008). The phenomena to which the phrase refers are generally termed "Social Facilitation." Anyone familiar with the behavior analytic account of the topic published by Bernard Guerin (1993) would realise the inadequacy of the term "Hawthorne Effect" but the phrase continues to be used. Another defeat for behavior analysis? Success requires more than simply having a correct analysis. One needs to find ways to make one's arguments persuasive. That in turn requires an awareness of some of the cultural forces which need to be overcome.

It is my impression that most of those people who have been contributing to the BFSR listserv discussions having been concentrating on ways of achieving fairly readily identifiable goals by employing methods of behavior change previously developed by behavior analysts. My experiences working in the field of child labor suggest to me that this may be to underestimate the complexity of the potential problems.

My interest in child labor grew out of my attempts to understand the behavior of my fellow psychologists. This covers not only questions of how they conduct their research and theorize but also how they come to study one topic rather than another. At the time, I was collaborating with fellow behaviorist, David Cornwell. With respect to child labor, our starting point was this. There is overwhelming evidence that child labor is common throughout the world. Although specialists in the field refer to possible psychological 
harm to the young workers, we can find hardly any psychologists researching child labor (Hobbs \& Cornwell, 1986).

When I began looking for ways of dealing with the "problems" of child labor, I soon realised that a behaviorist working in this field would face issues more complicated than those working in areas such as education or autism. In both of these areas, there would be a recognition that certain sorts of behavior change will be the goal. Although behaviorists define goals in distinctive ways, that the aim is to change behavior is not usually in itself in dispute. Educationists wish learners to acquire skills or knowledge. Parents hope their autistic children may be helped to be more "normal". Getting them to accept the value of setting goals in behavioural terms may be difficult but within the field of child labor the issues are more complex.

Those who object to child labor focus on the circumstances in which the child is placed rather than the behavior of the child itself. For example, it is common to hear it argued that that a child should be in a school rather than in a factory. Of course, the desire to see the child in school implies that education will lead to changes in the child, and to that extent we can envisage stating this in terms of behavioural goals. However, a key question has to be answered before we consider the child's education. How do we get the child out of the factory and into the school? The answer may vary considerably with specific circumstances. However, certain key considerations recur. Parents may resist moves to get the child out of the factory because the child's earnings may be crucial to their family incomes. (And we are often dealing with people living in extreme poverty.) Even where schools and teachers are available, the child and parents may prefer the factory because the quality of education provided is poor. One criterion of the success of schooling which will be important to the child and parents alike is what value the education provided has in influencing the child's later employment and earnings. The long term rewards of being educated may be difficult to demonstrate.

Some forms of child labor are so objectionable that there is widespread belief amongst campaigners that it a matter of urgency to remove the children from those circumstances as rapidly as possible. Child prostitutes and child soldiers fall into this category. However, it is worth noting some of the experiences of those who are trying to help such young people. However horrifying the circumstances may seem to those of us lucky enough to have better lifestyles, you cannot be certain that the young people will necessarily see the benefits of being "saved" from their situations. Their life circumstances may be such that they have had no opportunity to develop an understanding of what other possibilities might exist for them. Furthermore, once removed from their objectionable situation, there is an obligation not only to provide the food and shelter which were minimal benefits they had previously but also to provide a reinforcing alternative lifestyle.

Some organizations seek to undermine child labor by encouraging consumers to seek guarantees that the goods they are buying have not been produced by child workers. The limitations of such an approach may be illustrated by a case which emerged during the existence of the International Working Group on Child Labor, of which I was a member. A television company in Britain made a programme publicising the fact that 
clothes being sold in Britain were being made at a factory in Morocco employing child workers. Our local representative in Morocco established that as a result of the publicity the girls had been sacked. However, for almost all of them this meant economic hardship, for they had to take less well paid jobs, often of a worse sort than they had had in the factory (McKechnie \& Hobbs, 1998). It is not enough to undermine particular employers; one must consider what alternatives are open to the children concerned.

The many years I have spent dealing with the issues surrounding child labor have been largely devoted to the clarification of concepts and the accumulation of evidence. With respect to former, I have been concerned with the question of whether one can distinguish between "child labor" (bad) and "child employment" (good). In the past, many writers have confidently made such a distinction without paying much regard to seeking supporting evidence. Whilst work may have both beneficial and harmful features, it is necessary to examine this empirically. Along with non-behaviorist colleagues, I have tried to encourage this point of view by proposing a "Balance Model" (Hobbs \& McKechnie, 2006, 2007). In my country, Britain, again with non-behaviorist colleagues, I think I have helped to overcome a belief in governmental circles that it is uncommon for children to work. This has been achieved in part by simply collecting evidence (Hobbs, McKechnie \& Anderson, 2007). Of course, much work remains to be done to establish which aspects of their work is beneficial to the young workers and which aspects are harmful. But at least it is acknowledged that there is something there to consider. There is also the question of how one encourages the one and discourages the other. We have made only tentative initial steps at achieving behavior change.

One problem which I have had to face in only a relatively minor way is that of vested interests. This is because in Britain, where most of my research is focussed, the extent to which institutions profit from the employment of young workers is relatively limited. However, in many countries of the world employers will be very resistant to the undermining of the harmful effects of child labor because they benefit so much from the status quo. This is most obviously the case when the employers are large capitalist concerns. However, resistance is by no means restricted to them. For example, some children are sent by their parents to religious "schools" where labor may take up a large part of their time. Cultural support for child labor can be strong.

I have not made these points about my experiences researching child labor because I expect many behavior analysts to follow me into this field. However, I have the impression that many contributors to the listserv discussion have not had much direct personal experience of intervening in issues of major social concern. I may be wrong but contributors seem to be stressing the need to redefine problems in terms which make them amenable to solution by the application of behavioural technologies proven successful in other fields. This is fine but it is by no means the only requirement. The problem of achieving acceptance is great. Attention needs to be paid to how behavior analysis may be most persuasively advocated. I submit that part of the way to do this is to consider the cultural influences which affect whether innovations are accepted or not. That includes the non-acceptance of behaviorist proposals of the past. 


\section{HISTORICAL AND CULTURAL CONTEXT}

\section{REFERENCES}

Chiesa, M. \& Hobbs, S. (2008). Making sense of social research: How useful is the Hawthorne Effect? European Journal of Social Psychology, 38,67-74. http://dx.doi.org/10.1002/ejsp.401

Guerin, B. (1993). Social facilitation. Cambridge: Cambridge University Press.

Hackenbury, D. H. \& Hackenbury, S. E. (1997). Psychology. New York: Worth.

Hobbs, S. (2005). Beyond rumor and legend: Some aspects of academic communication. In G. Fine, V. Campion-Vincent, \& C. Heath (Eds.) Rumor mills: The social impact of rumor and legend (pp. 207-222). New York: Aldine Transaction.

Hobbs, S. \& Cornwell, D. (1986). Child labour: An underdeveloped topic in psychology. International Journal of Psychology, 21, 225-234.

http://dx.doi.org/10.1080/00207598608247587

Hobbs, S. \& Cornwell, D. (1991). A behavior analysis model of contemporary legend. Contemporary Legend, 1, 93-106.

Hobbs, S. \& McKechnie (2006). Child labor and behavior analysis. Brazilian Journal of Behavior Analysis, 2, 193-202.

Hobbs, S. \& McKechnie (2007). The Balance Model reconsidered: Changing perceptions of child employment. In B. Hungerland, M. Liebel, B. Milne, \& A. Wihstutz (Eds.) Working to be someone: Child focussed research and practice with working children (pp. 225-231).

London: Jessica Kingsley.

Hobbs, S., McKechnie, J. Anderson, S. (2007). Making child employment in Britain more visible. Critical Social Policy, 27, 415-425. http://dx.doi.org/10.1177/0261018307078849

Hobbs, S., McKechnie, J. \& Lavalette, M. (1999). Child labor: A world history companion. Santa Barbara CA: ABC-Clio.

McKechnie, J. \& Hobbs, S. (1998). Working children: Reconsidering the debates: Report of the International Working Group on Child Labour. Amsterdam: Defence for Children International.

McKechnie, J. \& Hobbs, S. (2002). Work by the young: The economic activity of school-aged children. In M. Tienda \& W. J. Wilson (Eds.) Youth in cities: A cross-national perspective (pp. 217-245). Cambridge: Cambridge University Press.

Keenan, M. (2004). Autism in Northern Ireland: The tragedy and the shame. The Psychologist, 17, 72-75.

Skinner, B. F. (1984). The shame of American education. American Psychologist, 39, 947-954. http://dx.doi.org/10.1037/0003-066X.39.9.947 